\title{
Pilot test of an interactive obesity treatment approach among employed adults in a university medical billing office
}

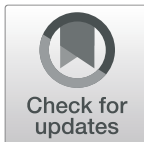

Rachel G. Tabak ${ }^{1 *}$, Jaime R. Strickland ${ }^{2}$, Bridget Kirk², Ryan Colvin², Richard I. Stein ${ }^{3}$, Hank Dart ${ }^{4}$, Graham A. Colditz ${ }^{5}$, Ann Marie Dale ${ }^{2}$ and Bradley A. Evanoff ${ }^{2}$

\begin{abstract}
Background: There is a need for workplace programs promoting healthy eating and activity that reach low-wage employees and are scalable beyond the study site. Interventions designed with dissemination in mind aim to utilize minimal resources and to fit within existing systems. Technology-based interventions have the potential to promote healthy behaviors and to be sustainable as well as scalable. We developed an interactive obesity treatment approach (iOTA), to be delivered by SMS text messaging, and therefore accessible to a broad population. The aim of this pilot study was to evaluate participant engagement with, and acceptability of, this iOTA to promote healthy eating and activity behaviors among low-wage workers with obesity.

Methods: Twenty participants (self-reporting body mass index $\geq 30 \mathrm{~kg} / \mathrm{m}^{2}$ ) of a single workgroup employed by a university medical practice billing office had access to the full intervention and study measures and provided feedback on the experience. Height and weight were measured by trained research staff at baseline. Each participant was offered a quarterly session with a health coach. Measured weight and a self-administered survey, including dietary and activity behaviors, were also collected at baseline, 3, 6, 12, 18, and 24 months. Participant engagement was assessed through responsiveness to iOTA SMS text messages throughout the 24-month pilot. A survey measure was used to assess satisfaction with iOTA at 3 months. Due to the small sample size and pilot nature of the current study, we conducted descriptive analyses. Engagement, weight change, and duration remaining in coaching are presented individually for each study participant.
\end{abstract}

Results: The pilot was originally intended to last 3 months, but nearly all participants requested to continue; we thus continued for 24 months. Most (14/20) participants remained in coaching for 24 months. At the 3-month follow-up, eight (47\%) of the remaining 17 participants had lost weight; by 24 months, five (36\%) of the remaining 14 participants had lost weight (one had bariatric surgery). Participants reported very high satisfaction.

Conclusions: This pilot provides important preliminary results on acceptability and participant engagement with iOTA, which has significant potential for dissemination and sustainability.

\footnotetext{
* Correspondence: rtabak@wustl.edu

${ }^{1}$ The Brown School, Washington University in St. Louis, 1 Brookings Dr, St. Louis, MO 63130, USA

Full list of author information is available at the end of the article
}

(c) The Author(s). 2020 Open Access This article is licensed under a Creative Commons Attribution 4.0 International License, which permits use, sharing, adaptation, distribution and reproduction in any medium or format, as long as you give appropriate credit to the original author(s) and the source, provide a link to the Creative Commons licence, and indicate if changes were made. The images or other third party material in this article are included in the article's Creative Commons licence, unless indicated otherwise in a credit line to the material. If material is not included in the article's Creative Commons licence and your intended use is not permitted by statutory regulation or exceeds the permitted use, you will need to obtain permission directly from the copyright holder. To view a copy of this licence, visit http://creativecommons.org/licenses/by/4.0/ The Creative Commons Public Domain Dedication waiver (http://creativecommons.org/publicdomain/zero/1.0/) applies to the data made available in this article, unless otherwise stated in a credit line to the data. 


\section{Background}

Healthy eating and activity are important to prevent obesity and chronic diseases such as diabetes. Low-wage workers bear a disproportionate share of the chronic disease burden [1-6] yet have more limited access to workplace resources that promote healthy eating and activity $[7,8]$. It is therefore critical that programs to support health-promoting behaviors be easy to access and acceptable to this population. Often, even when such resources are available in a worksite, low-wage workers are less likely to engage with them due to a number of barriers including acceptability and social support [8-19].

Despite the benefits of existing workplace programs that promote healthy eating and activity, limitations remain [20-25], particularly in reaching low-wage employees. Further, there has been limited ability to scale effective programs beyond the study site [26]. Interventions designed with dissemination in mind aim to utilize minimal resources and to fit well within existing systems [27].

Technology-based interventions have the potential to promote healthy behaviors and to be sustainable as well as scalable [23, 28, 29] A number of technological methods have been explored to support health behaviors related to obesity [23, 29-31]. Many of these methods, however, require specific hardware/software and/or time on the part of participants, making them out of reach for or unappealing to individuals with limited resources. SMS (short message service) text messaging is ubiquitous, inexpensive, standardized across mobile phone platforms, and does not require additional software, applications, mobile phone data plan, or internet access, making it an ideal system to reach low-wage workers [32-37]. In response to this, we developed an interactive obesity treatment approach (iOTA), designed to be delivered by SMS text messaging, and therefore accessible to a broad population. Development of this SMS textbased iOTA has been described previously [38]. Briefly, this intervention was adapted from an evidence-based weight loss program [39, 40] and includes a baseline meeting with a health coach at which three behavior change goals are selected. Each participant then receives interactive, automatic text messages which include weekly weight and goal achievement check-ins as well as one behavioral tip per week for each goal and periodic motivational messages. iOTA goals are fully described elsewhere [41]; sample behavioral tip messages include: "Don't tempt yourself - Empty the fridge of sugary drinks. And keep low-calorie choices handy, like water and unsweetened coffee or tea." and "Don't worry. There are healthy fast food options. Try grilled chicken, turkey sandwiches without cheese \& mayo, and veggie stir-fry with brown rice." Additional coaching sessions to reflect on goal progress and brainstorm ways to address barriers to goal achievement occur quarterly. At these sessions, coaches provide education and resources related to chosen goal topics, and participants have the option to change goals. Pilot testing of this iOTA was conducted to understand how participants engage with the intervention, participant satisfaction, and to summarize lessons learned for larger-scale evaluation.

This study fills an important gap in reporting on engagement with an SMS text-based workplace intervention designed for dissemination and sustainability. The aim of this pilot study was to evaluate participant engagement with and acceptability of this iOTA to promote healthy eating and activity behaviors among low-wage workers with obesity.

\section{Methods}

\section{Study design}

This pilot study allowed for preliminary evaluation of the iOTA and measures used in assessment of behavior change among low-wage employees. Participants in this pilot had access to the full intervention (weekly SMS text messaging and quarterly health coach sessions, where they received handouts related to their discussions) and study measures and provided feedback on the experience. Participants provided informed consent to participate in the initial pilot and additional consent to extend the pilot. To compensate for their time completing data collection, participants received $\$ 25$ at baseline, $\$ 50$ at 3 months, $\$ 20$ at 6 months, $\$ 30$ at 12 months, $\$ 20$ at 18 months, and $\$ 30$ at 24 months. The study was approved by the Human Research Protection Office at Washington University in St. Louis (\#201609029).

\section{Setting and participants}

A workgroup from a university medical practice billing office was recruited to participate in the pilot study. Given the focus of the intervention on low-wage employees, this workgroup was selected to mirror the inclusion criteria employed in the larger trial to evaluate iOTA, including a high proportion of lower wage workers. Recruitment criteria for the larger trial are described fully elsewhere [41]. From this group, employees self-reporting a body mass index (BMI) greater than $30 \mathrm{~kg} / \mathrm{m}^{2}$ were invited to participate and were screened for exclusion criteria: currently pregnant or nursing, bariatric surgery in the last 12 months, current cancer diagnosis, or planning to leave the work unit within the next month. Based on previous experience with pilot testing interventions, 20 participants was thought to be a reasonable recruitment goal that would be logistically feasible and still yield enough data to understand participant engagement with and acceptability of iOTA, as well as to determine major changes needed to the intervention. Since the goal for the pilot was 20 participants, the first 20 eligible participants to volunteer were included, though more than 20 expressed interest. Height 
and weight were measured by trained research staff at baseline to verify BMI prior to enrollment.

\section{Measures \\ Program engagement}

Administration of the iOTA via an interactive, automated SMS text-messaging program allowed for assessment of participant engagement with the program, based on responsiveness to iOTA text messages. The percent of weeks during which participants responded to text message prompts (to report progress on weight and goal attainment) was assessed throughout each participant's enrollment in the pilot. As part of the iOTA protocol, if a participant reported meeting their goal 3 weeks in a row, they were offered the opportunity (through the automated SMS texting system) to make the goal more challenging or maintain their original goal. The success rate for each participant was explored based on their self-report of goal achievement across all weeks. These data were collected throughout the 24-month pilot.

\section{Eating and activity behavior}

Dietary behaviors were assessed using the Rapid Eating Assessment for Participants (REAP-S) measure [42, 43]. Physical activity was measured with the job-related and leisure time domains of the International Physical Activity Questionnaire (IPAQ) [44, 45]. These self-report measures were collected in baseline and follow-up surveys at 3, 6, 12,18 , and 24 months. The baseline survey also included demographics and psychosocial supports for eating and physical activity.

\section{Height and weight}

Height and weight were measured by trained research staff at baseline. These staff also measured each participant's weight at each quarterly coaching session; 3, 6, 12, 18 , and 24-month weights are presented, as they correspond to survey data collection.

\section{Satisfaction}

A survey measure designed specifically for the study was used to assess satisfaction with and suggested modifications for iOTA at 3 months. Questions with Likert-type responses $(1=$ strongly disagree, $2=$ disagree, $3=$ neutral, $4=$ agree; $5=$ strongly agree) asked about perceptions of the overall program, the health coaching interaction, the text messaging, and overall perceived benefits to participation. Participants also had the opportunity to respond to open-ended questions asking about their favorite parts of iOTA, what they would change, and to provide any additional feedback.

\section{Analysis}

Due to the small sample size and pilot nature of the current study, we conducted descriptive analyses. Engagement, weight change, and length of time remaining in coaching are presented individually for each study participant. The percent of participants reporting any, $3 \%$, or $5 \%$ weight loss, along with mean weight change in pounds, are presented at each time point. Eating behaviors were summarized with the mean REAP-S score, and the number and percent of participants are reported for several individual items (e.g., often skip breakfast), which were dichotomized to "often" (usually, often) and "not often" (sometimes, rarely, never). Finally, several items ask participants to report the number of days in a typical week a behavior was completed (e.g., bring food from home); these were summarized to mean number of days per week. Activity is summarized both continuously (mean of the total minutes per week walking, doing moderate activity, and/ or doing vigorous activity) and in terms of the number and percent of participants reporting they met the Centers for Disease Control and Prevention physical activity recommendation of 150 min moderate to vigorous physical activity (MVPA) per week. To better understand how pilot participants were using the iOTA, the goals selected and percent of weeks participants reported successfully achieving each goal is summarized as are means for items assessing program satisfaction.

\section{Results}

The pilot was originally intended to last 3 months, but nearly all participants requested that the pilot study continue after that time; we thus continued for 21 more months (24 months total, the duration of the full clinical trial testing the iOTA intervention, which incorporated the feedback from the current pilot) [41]. Participants were predominantly female $(85 \%)$. Few participants had college degrees (15\%). Among those who reported income, half made less than $\$ 21$ per hour; more than half of participants reported a health condition potentially related to obesity (Table 1 ).

Overall, there were very high rates of engagement across the 24 months (Table 2). Two participants discontinued participation prior to the first follow-up session. Two participants completed only the originally described 3 months while most participants elected to remain in coaching for extended time: one to 9 months, another one continuing to 12 months, and the remaining 14 participants continued to participate in coaching for the entire 24 months. Of those that discontinued, two participants left the workgroup (one prior to 3 months and one after 9 months), so we were not able to continue the follow-up after they left and were dropped from study participation. From Table 2, it appears that participants continued to respond to prompts for most 
Table 1 Distribution of baseline characteristics, iOTA pilot participants

\begin{tabular}{|c|c|}
\hline & Overall \\
\hline & $n=20$ \\
\hline \multicolumn{2}{|l|}{ Age category in years } \\
\hline $30-40$ & $7(35.0)$ \\
\hline $41-50$ & $4(20.0)$ \\
\hline $51-60$ & $9(45.0)$ \\
\hline Gender = female & $17(85.0)$ \\
\hline Race $=$ White $/$ Caucasian & $10(50.0)$ \\
\hline \multicolumn{2}{|l|}{ Education } \\
\hline High school/GED & $2(10.0)$ \\
\hline Some college & $15(75.0)$ \\
\hline College-Bachelor's degree & $3(15.0)$ \\
\hline \multicolumn{2}{|l|}{ Hourly pay } \\
\hline$\$ 10.0-15.9$ & $1(5.0)$ \\
\hline$\$ 16.0-20.9$ & $7(35.0)$ \\
\hline$\$ 21.0-25.9$ & $4(20.0)$ \\
\hline$\$ 26.0-30.9$ & $0(0.0)$ \\
\hline$\$ 31.0+$ & $4(20.0)$ \\
\hline Not reported & $4(20.0)$ \\
\hline \multicolumn{2}{|l|}{ Marital status } \\
\hline Never married & $3(15.0)$ \\
\hline Married & $13(65.0)$ \\
\hline Divorced/separated & $2(10.0)$ \\
\hline Member of an unmarried couple & $2(10.0)$ \\
\hline $\mathrm{BMI}, \mathrm{kg} / \mathrm{m}^{2}$ & $35.6(33.7,40)$ \\
\hline \multicolumn{2}{|l|}{ BMI by category } \\
\hline Normal weight (BMI < 25.0) & $0(0.0)$ \\
\hline Overweight (BMI 25.0-29.9) ${ }^{\mathrm{a}}$ & $1(5.0)$ \\
\hline Obese (BMI $\geq 30$ ) & $19(95.0)$ \\
\hline SF-8 physical component score & $48(41,53.4)$ \\
\hline SF-8 mental component score & $47.1(38.3,56.2)$ \\
\hline Diabetes $d x$ in past 6 months & $1(5.0)$ \\
\hline Hypertension $\mathrm{dx}$ in past 6 months & $10(50.0)$ \\
\hline Hypercholesterolemia $d x$ in past 6 months & $6(30.0)$ \\
\hline Have $\geq 1$ conditions listed above & $11(55.0)$ \\
\hline Have $\geq 2$ conditions listed above & $6(30.0)$ \\
\hline Usual hours worked per week & $40(40,40)$ \\
\hline Work non-day shifts & $1(5.0)$ \\
\hline Coworker support scale ${ }^{b}$ & $8.5(7.8,10.2)$ \\
\hline Supervisor support scale ${ }^{b}$ & $10.5(8,12)$ \\
\hline Participated in $\geq 1$ wellness program in the workplace & $17(85.0)$ \\
\hline
\end{tabular}

Presented are $n$ (\%) for categorical variables, median (25th, 75th percentile) for continuous variables

${ }^{a}$ One participant lost weight between the self-report assessment of eligibility and the baseline weight and thus moved to overweight status $(B M I=29.2$, initial, BMI based on self-reported weight $=30.4)$

${ }^{\mathrm{b}}$ Range $0-12$, with higher scores indicating more support weeks leading up to the time they stopped participating in coaching or the end of the 24-month pilot. Table 2 also depicts the range of weight change among participants (excluding a 97-pound weight loss by the participant who had bariatric surgery during the study), from a 41-pound weight loss to a 44-pound weight gain.

Within the initial pilot phase, eight $(47 \%)$ of the original 17 participants with 3-month data had lost weight (Table 3). By 24 months, four (31\%) of the remaining 13 participants had lost weight, and three of these (23\%) had lost $5 \%$ of their body weight. The median weight change was a gain at all time points $(8.6,25$ th, 75 th percentile $-2.2,16.3$ pounds at 24 months), but among those who lost weight, the median weight loss increased from 3 to 24 months.

Behavior results across measurement time points are shown in Table 4. Given the small sample size, it is not possible to compare among time points, but there do seem to be positive trends in behavior measures. In particular, the overall dietary behaviors' (i.e., REAP-S) score and the total minutes of physical activity reported per week appeared to improve over the 24 months of followup, with median minutes of self-reported activity per week at baseline of 100 (25th, 75th percentile 37.5, 150) compared to 180 (25th, 75th percentile $85,242.5$ ) minutes at 24-month follow-up

The most commonly selected goal was getting brisk activity (Table 5), with 14 participants selecting this goal. Participants had the opportunity to change goals or select to continue with their previous goal; thus, the number of participants for brisk activity is interpreted as follows: this goal was selected by 14 individuals at 74 coaching sessions. These 14 participants responded to prompts about their progress on this goal in 667 weeks and reported successfully meeting their brisk activity goal $49 \%$ of the time. Several other goals were selected by five or more participants. All goals except low-fat dairy were selected by at least one participant, though increasing whole grain intake and decreasing total calories were each selected by only one participant. All pilot participants had a physical activity goal (i.e., brisk activity or steps) at some point throughout the program. The percent of participants who selected each goal and who reported achieving the goal at some point during the 24 months of follow-up varied considerably across goals.

Overall, participants reported very high satisfaction with the program; mean scores for each item were near 5 , indicating strong agreement with the following statements: the advice given in my coaching session was helpful (mean $=4.9)$; the information given was relevant (mean $=4.8$ ); the health coach was motivating in terms of getting/staying physically active and/or eating nutritiously (mean $=4.9$ ); the health coach was understanding and supportive $($ mean $=4.9$ ); the overall level of service 
Table 2 Participant responsiveness over time and individual weight change (Ibs)

\begin{tabular}{|c|c|c|c|c|c|c|c|c|c|}
\hline \multirow[b]{2}{*}{ Participant } & \multicolumn{5}{|c|}{ Weekly text message response, ( $N$ responses, \% of possible weeks to respond)) } & \multirow{2}{*}{$\begin{array}{l}\text { Last } \\
\text { coaching } \\
\text { session } \\
\text { attended }\end{array}$} & \multirow{2}{*}{$\begin{array}{l}\text { Baseline } \\
\text { weight }\end{array}$} & \multirow{2}{*}{$\begin{array}{l}\text { Final } \\
\text { weight }\end{array}$} & \multirow{2}{*}{$\begin{array}{l}\text { Final } \\
\text { weight } \\
\text { change }\end{array}$} \\
\hline & 3 months & 6 months & 12 months & 18 months & 24 months & & & & \\
\hline 1 & $11(84.6)$ & $24(92.3)$ & $50(96.1)$ & $72(92.3)$ & $85(81.7)$ & 24 months & 182.8 & 153.0 & -29.8 \\
\hline $2^{\mathrm{a}}$ & $12(92.3)$ & $25(96.1)$ & $50(96.1)$ & $75(96.1)$ & $95(91.3)$ & 24 months & 291.6 & 194.2 & -97.4 \\
\hline 3 & $12(92.3)$ & $25(96.1)$ & $50(96.1)$ & 70 (89.7) & 92 (88.4) & 24 months & 221.0 & 229.4 & +8.4 \\
\hline 4 & $12(92.3)$ & 25 (96.1) & 50 (96.1.0) & 75 (96.1) & $100(96.1)$ & 24 months & 235.8 & 252.1 & +16.3 \\
\hline 5 & $13(100.0)$ & $26(100.0)$ & $52(100.0)$ & 78 (100.0) & $104(100.0)$ & 24 months & 233.4 & 242.0 & +8.6 \\
\hline 6 & $12(92.3)$ & $12(46.1)$ & $12(23.0)$ & $12(15.3)$ & $12(11.5)$ & 3 months & 198.0 & 188.0 & -10.0 \\
\hline 7 & $11(84.6)$ & $12(46.1)$ & $12(23.0)$ & $12(15.3)$ & $12(11.5)$ & 3 months & 281.8 & 298.2 & +16.4 \\
\hline 8 & $12(92.3)$ & $24(92.3)$ & 45 (86.5) & 45 (57.6) & $45(43.2)$ & 9 months & 235.0 & 248.0 & +13.0 \\
\hline 9 & $13(100.0)$ & $26(100.0)$ & $49(94.2)$ & 72 (92.3) & $96(92.3)$ & 24 months & 250.4 & 294.4 & +44.0 \\
\hline 10 & $13(100.0)$ & $26(100.0)$ & $52(100.0)$ & 77 (98.7) & 101 (97.1) & 24 months & 251.2 & 256.8 & +5.6 \\
\hline 11 & $13(100.0)$ & $26(100.0)$ & $52(100.0)$ & 75 (96.1) & 99 (95.1) & 24 months & 250.2 & 272.8 & +22.6 \\
\hline $12^{\mathrm{b}}$ & $5(38.4)$ & $5(19.2)$ & $5(9.6)$ & $5(6.4)$ & $5(4.8)$ & $\mathrm{n} / \mathrm{a}$ & 237.0 & $\mathrm{n} / \mathrm{a}$ & $\mathrm{n} / \mathrm{a}$ \\
\hline 13 & $11(84.6)$ & $19(73.0)$ & 27 (51.9) & $41(52.5)$ & $45(43.2)$ & 24 months & 188.0 & 207.8 & +19.8 \\
\hline 14 & $8(61.5)$ & 15 (57.6) & 27 (51.9) & $29(37.1)$ & $29(27.8)$ & 12 months & 232.6 & 245.8 & +13.2 \\
\hline $15^{b}$ & $9(69.2)$ & $11(42.3)$ & $11(21.1)$ & $11(14.1)$ & $11(10.5)$ & $\mathrm{n} / \mathrm{a}$ & 182.6 & $\mathrm{n} / \mathrm{a}$ & $\mathrm{n} / \mathrm{a}$ \\
\hline 16 & 7 (53.8) & 10 (38.4) & $23(44.2)$ & $42(53.8)$ & $55(52.8)$ & 24 months & 239.4 & 253.4 & +14.0 \\
\hline 17 & $12(92.3)$ & $25(96.1)$ & $51(98.0)$ & 77 (98.7) & 103 (99.0) & 24 months & 203.2 & 215.8 & +12.6 \\
\hline 18 & $12(92.3)$ & $24(92.3)$ & 43 (82.6) & 66 (84.6) & 77 (74.0) & 24 months & 355.0 & 352.8 & -2.2 \\
\hline 19 & $13(100.0)$ & $25(96.1)$ & $51(98.0)$ & 76 (97.4) & $100(96.1)$ & 24 months & 170.0 & 154.5 & -15.5 \\
\hline 20 & $13(100.0)$ & $26(100.0)$ & $49(94.2)$ & 73 (93.5) & $93(89.4)$ & 24 months & 222.0 & 180.6 & -41.4 \\
\hline
\end{tabular}

Proportion of weekly SMS text messages to which participant responded, grouped by 3-month intervals corresponding to coaching sessions. A response was defined as participant report of weekly weight or goal completion status

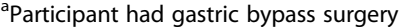

${ }^{b}$ Participant did not attend any follow-up coaching sessions

and support was good (mean $=4.8$ ); the text message check-ins have helped me to be active and/or eat nutritiously (mean $=4.6$ ); and the handouts helped me to be active and/or eat nutritiously ( mean $=4.4)$.

\section{Discussion}

This pilot study demonstrates participant engagement with and acceptability of an SMS text-based iOTA among a group of office workers. While retention was quite high (17 of $20,85 \%$ ) over the planned 3-month pilot, engagement was further demonstrated by the 14 (70\%, including the participant who had bariatric surgery) who continued to participate in coaching for 24 months (21 months longer than initially intended). Further, the pilot demonstrated high response rates to iOTA texts and very strong satisfaction with the program.

Few studies have tested interventions in low-wage working populations, and in particular, few have focused on interventions that can be disseminated and sustained. Due to the enthusiasm of participants, this pilot is

Table 3 Weight change (lbs) from baseline

\begin{tabular}{|c|c|c|c|c|c|c|}
\hline $\begin{array}{l}\text { Measurement } \\
\text { time point }\end{array}$ & $\begin{array}{l}\text { Lost any } \\
\text { weight }\end{array}$ & $\begin{array}{l}\text { Lost } \geq 3 \% \\
\text { of weight }\end{array}$ & $\begin{array}{l}\text { Lost } \geq 5 \% \\
\text { of weight }\end{array}$ & $\begin{array}{l}\text { Weight } \\
\text { change }^{a} \text {, Ibs }\end{array}$ & Weight loss ${ }^{\mathrm{b}}$, Ibs & $\begin{array}{l}\text { Maximum weight } \\
\text { loss, lbs }\end{array}$ \\
\hline 3 months $(N=17)$ & $8(47.1)$ & $3(17.6)$ & $1(5.9)$ & $+2.2(-5.6,5)$ & $-6.3(-7.8,-2.1)$ & -14.2 \\
\hline 6 months $(N=15)$ & $6(40.0)$ & $2(13.3)$ & $1(6.7)$ & $+1.8(-1.6,7)$ & $-3.7(-8,-1)$ & -10.6 \\
\hline 12 months $(N=14)$ & $4(28.6)$ & $2(14.3)$ & $2(14.3)$ & $+7.4(0.1,12.6)$ & $-9.8(-19.1,-4.3)$ & -34.6 \\
\hline 18 months $(N=13)$ & $6(46.2)$ & $2(15.4)$ & $2(15.4)$ & $+4.8(-4.5,12.3)$ & $-5.2(-18.9,-2.2)$ & -46.0 \\
\hline 24 months $(N=13)$ & $4(30.8)$ & $3(23.1)$ & $3(23.1)$ & $+8.6(-2.2,16.3)$ & $-22.7(-32.7,-12.2)$ & -41.4 \\
\hline
\end{tabular}

Presented are $n$ (\%) for categorical variables and median (25th, 75th percentile) for continuous variables. Participant who had bariatric surgery not included ${ }^{a}$ Overall change in weight from baseline. Includes all participants who had weight measured

beight change, limited to participants who lost weight 
Table 4 Health behaviors by time point

\begin{tabular}{|c|c|c|c|c|c|c|}
\hline & $\begin{array}{l}\text { Baseline } \\
(N=19)\end{array}$ & $\begin{array}{l}3 \text { months } \\
(N=17)\end{array}$ & $\begin{array}{l}6 \text { months } \\
(N=15)\end{array}$ & $\begin{array}{l}12 \text { months } \\
(N=14)\end{array}$ & $\begin{array}{l}18 \text { months } \\
(N=13)\end{array}$ & $\begin{array}{l}24 \text { months } \\
(N=11)\end{array}$ \\
\hline \multicolumn{7}{|l|}{ REAP-S results } \\
\hline REAP-S score ${ }^{a}$ & $24(22,27.5)$ & $21.5(18.8,23.2)$ & $21(19,24.5)$ & $20.5(18.2,22.5)$ & $21(19,22)$ & $20(20,23)$ \\
\hline Often consume fried foods & $2(10.5)$ & $1(6.2)$ & $0(0.0)$ & $0(0.0)$ & $0(0.0)$ & $1(9.1)$ \\
\hline Often consume sweets & $7(36.8)$ & $0(0.0)$ & $1(6.7)$ & $2(14.3)$ & $0(0.0)$ & $0(0.0)$ \\
\hline Often consume sugary drinks & $13(68.4)$ & $1(6.2)$ & $2(13.3)$ & $0(0.0)$ & $0(0.0)$ & $1(9.1)$ \\
\hline Often skip breakfast & $5(26.3)$ & $1(6.2)$ & $1(6.7)$ & $2(14.3)$ & $0(0.0)$ & $1(9.1)$ \\
\hline $\begin{array}{l}\text { Bring food from home, days } \\
\text { per week }\end{array}$ & $4(2,5)$ & $4.5(3,5)$ & $5(3,5)$ & $4(3,4.8)$ & $4(3,5)$ & $4(3,5)$ \\
\hline Buy food at work, days per week & $1(0,1)$ & $0(0,0.2)$ & $0(0,0.5)$ & $0(0,1)$ & $0(0,1)$ & $0(0,1)$ \\
\hline $\begin{array}{l}\text { Minutes of self-reported activity } \\
\text { per week }\end{array}$ & $100(37.5,150)$ & $195(50,285)$ & $190(30,392.5)$ & $105(0,285)$ & $100(45,250)$ & $180(85,242.5)$ \\
\hline $\begin{array}{l}\text { Get recommended level of exercise } \\
\text { (150 min MVPA/week) }\end{array}$ & $8(42.1)$ & $4(21.1)$ & $6(31.6)$ & $6(31.6)$ & $3(23.1)$ & $5(45.5)$ \\
\hline
\end{tabular}

Presented are $n$ (\%) for categorical variables and median (25th, 75th percentile) for continuous variables. Participant who had bariatric surgery not included ${ }^{a}$ REAP-S score ranges from 13 to 39. Lower scores represent healthier choices

${ }^{b}$ Computed by adding responses to all three survey questions (minutes per week walking, doing moderate activity, doing vigorous activity)

Table 5 iOTA goal selection and completion

\begin{tabular}{|c|c|c|c|c|}
\hline Goal & $N$ participants & $\begin{array}{l}\text { Times chosen at } \\
\text { coaching sessions }\end{array}$ & $\begin{array}{l}\text { Weeks participants } \\
\text { responded to goal } \\
\text { prompt }\end{array}$ & $\begin{array}{l}\text { Average goal } \\
\text { success }^{\mathrm{a}}(\%)\end{array}$ \\
\hline All goals & 19 & 309 & 2965 & 56.9 \\
\hline Brisk activity & 14 & 74 & 667 & 49.1 \\
\hline Steps & 11 & 39 & 375 & 31.2 \\
\hline Healthy breakfast & 11 & 35 & 345 & 68.5 \\
\hline Sugary drinks & 9 & 32 & 347 & 78.0 \\
\hline Purchased food_-meals at home & 7 & 23 & 218 & 71.2 \\
\hline Screen time snacking & 7 & 18 & 195 & 79.7 \\
\hline Fruits and vegetables & 7 & 15 & 166 & 45.5 \\
\hline High-calorie snacks & 6 & 19 & 208 & 65.0 \\
\hline Self-monitoring of diet & 5 & 6 & 62 & 13.8 \\
\hline Vegetables & 5 & 5 & 68 & 83.0 \\
\hline Portion control & 4 & 14 & 81 & 87.8 \\
\hline Free food_limit at work & 4 & 6 & 68 & 76.0 \\
\hline High-fat meats & 3 & 9 & 26 & 57.1 \\
\hline Purchased food_limit at work & 3 & 5 & 51 & 97.0 \\
\hline Added calories & 2 & 4 & 46 & 24.6 \\
\hline Purchased food-healthy meal choices & 2 & 3 & 32 & 90.9 \\
\hline Total calories & 1 & 1 & 6 & 0.0 \\
\hline Whole grains & 1 & 1 & 4 & 100.0 \\
\hline Low-fat dairy & 0 & 0 & 0 & $\mathrm{~N} / \mathrm{A}$ \\
\hline
\end{tabular}

Participant who had bariatric surgery not included

${ }^{\text {a }}$ As reported in SMS text message responses 
considerably longer than many pilots of text-based interventions; for example, a review of text-messaging interventions to prevent cardiovascular disease found pilot studies ranged from 1 to 4 weeks [46]. Several studies looking at engagement with technology-based interventions using media besides texting and weight outcomes have demonstrated the importance of engagement with the intervention in promoting weight change. One study found a significant association between weight loss and engagement with an online weight loss program [47]. Another found those with higher engagement in a mobile phone-based coaching intervention, which included intensive health coaching via live video, phone, and text message through an app, lost more weight than those with lower levels of engagement [48]. An intervention delivered through mobile phones, to pregnant women [49], which incorporated the self-assessment and goal setting components into the mobile platform in addition to goal setting, found $45 \%$ completing the assessment step, $25 \%$ completing the goal setting step, and $23 \%$ competing the self-monitoring steps, with relationships between weight outcomes and engagement varying by BMI [50]. Therefore, though the impact on weight in the current pilot was not as clear, the finding that not only did participants want to continue in IOTA but that they were highly engaged is encouraging. Involving both SMS text messaging and in-person coaching may have led to higher engagement, which has the potential to increase intervention impact. Further, this study was conducted among a group of employees working together, which could enhance social support; iOTA was deigned to be nested within a workgroup intervention, which is why the larger trial evaluating iOTA is cluster randomized at the workgroup level.

While not designed or powered to determine efficacy, preliminary findings suggest a trend toward increase physical activity and some amount of weight loss among more than one quarter of participants. Three (23\%) of the 13 participants remaining in the study at 24 months lost 5\% of their body weight, which is in line with findings from a 2015 review of real-world diabetes prevention programs. This review found the percent of participants successfully achieving a 5\% weight loss ranged from 20 to $64 \%$ and a mean weight loss across studies of $10.1 \mathrm{~kg}$ (22.3 lbs.); weight change in the current study was a gain of 4.8 pounds. This should be interpreted with caution given recent findings from a large trial of an intervention among middle- and low-wage workers in a warehouse setting, which found positive outcomes in terms of self-reported health behaviors, but no benefits in clinical outcomes [51]. However, other interventions employing text messages to promote weight loss have been successful in patients with prediabetes [52].

Important lessons related to participant expectations learned in the course of this pilot study informed the larger, subsequent evaluation of iOTA. For example, the pilot study began over the winter holidays, a time which is commonly related to weight gain [53-57]. This may have driven enthusiasm among participants and encouraged longer participation, heightening the importance of a randomized study, where participants in both intervention and control arms begin the study at similar times of year, so such seasonal effects do not impact conclusions related to intervention engagement or efficacy. Another important lesson was related to scales used for selfmonitoring of weight. For self-monitoring, in particular for responding to the weekly weight check-in texts, participants were encouraged to use either home scales or a scale provided by the research team that was left at the worksite and to use the same scale each time. However, when weight was assessed using a study scale (calibrated monthly and brought on-site for study measurements), the weights were different from those participants expected based on their ongoing self-weighing, perhaps as participants were weighing at different times of day or in different clothing. This led to disappointment and discouragement, as participants thought they were losing weight based on self-monitoring, but may not have seen the same success in more-accurate measurement sessions. This suggested the importance of calibrating scales provided to worksites for self-monitoring, providing instructions on weighing at consistent times of day in similar amounts of clothing, as well as managing expectations with participants up-front about the potential for different readings on different scales and measurement issues.

This pilot had additional implications for conducting the larger study, related to goals and message communication. During the initial phase, the pilot participants received four reminder messages each Monday: one to remind them they would be asked about their weight and then one for each of their goals reminding them what their goal was and that they would be asked to report on that goal the next day (Tuesday). Since participants felt this was an excessive number of messages, the reminder system was adjusted such that participants started receiving just one message on Mondays reminding them they will be asked to report their weight and goals on the following day and that if they would like a reminder of what goals they had selected, they could request this by text. The pilot of iOTA also led to a change in goal selection instructions. Initially, participants were required to pick three goals, but based on feedback from participants indicating this could be too much to work on at once, and that they may be more successful focusing on a smaller number of goals, the instructions were modified to encourage participants to pick up to three goals. While a detailed description of the adaptation of an evidence-based intervention $[39,40]$ to develop the current iOTA has 
been described elsewhere [38], this pilot work was critical to preparing iOTA for evaluation in a randomized trial.

This study makes an important contribution to the literature in demonstrating the potential for this type of technology-based intervention to reach participants and for participants to be highly engaged. Further, lessons learned can inform a larger trial as well as other programs targeting behavior change among low-wage employees, particularly those utilizing SMS text messaging. These lessons include incorporating ongoing methods to check participant engagement. For the current pilot, this took the form of automatic generation of reports to alert coaches when participants indicate not meeting their goals several weeks in a row, those not responding to text message prompts, and those gaining weight, so a coach could reach out directly, providing extra reinforcement only to those who needed it. Additionally, as mentioned, the pilot information can be helpful for future studies to advise participants about the potential for measurement error when home scales are used for self-monitoring of weight. This can help set appropriate expectations and prevent the demoralizing experience participants reported when they found out their weight had not changed as they thought it had.

As a pilot, this study is limited by the small sample size and the single workgroup. An ongoing study is currently testing the final iOTA among a larger number of workgroups and hundreds of participants using a cluster randomized design [41]. This will not only allow for efficacy testing, but will also provide additional statistical power to explore questions, such as whether engagement is associated with weight loss success, and will allow for exploration of what goals might be most strongly associated with engagement and weight loss.

\section{Conclusions}

This pilot provides important preliminary results on high acceptability and good participant engagement with an SMS-based intervention intended for low-wage workers, with significant potential for dissemination and sustainability. Lessons learned from this pilot such as modifications to instructions for goal selection and message timing were important in enhancing the larger trial evaluating iOTA.

\section{Abbreviations \\ SMS: Short message service; BMI: Body mass index; iOTA: Interactive obesity treatment approach; REAP-S: Rapid Eating Assessment for Participants; IPAQ: International Physical Activity Questionnaire; MVPA: Moderate to vigorous physical activity}

\section{Acknowledgements}

The authors would like to thank Skye Buckner-Petty for his efforts in the data management and preliminary analyses for this study.

\section{Authors' contributions}

RGT participated in the iOTA development and pilot process and developed the manuscript. JRS managed the pilot study and participated in the iOTA development process. BK participated in the data collection and pilot intervention implementation. RC participated in the data management, analysis, and interpretation. RIS, HD, GAC, and AMD contributed to the iOTA development and pilot process. BAE participated in the iOTA development process and designed and managed the study. All authors contributed to interpretation of the study and preparation of the manuscript. The authors read and approved the final manuscript.

\section{Funding}

This publication was made possible by Grant Numbers R01DK103760 and P30DK092950 from the National Institute of Diabetes and Digestive and Kidney Diseases (NIDDK). This project was also supported by the Diabetes Research Center (DRC) at Washington University, grant number 5P30DK020579, and by the Washington University Institute of Clinical and Translational Sciences grant UL1TR002345 from the National Center for Advancing Translational Sciences (NCATS) of the National Institutes of Health $(\mathrm{NIH})$. The content is solely the responsibility of the authors and does not necessarily represent the official view of the National Institutes of Health. These funding bodies had no role in the design of the study and collection, analysis or interpretation of data, or in writing the manuscript.

\section{Availability of data and materials}

The datasets used and/or analyzed during the current study are available from the corresponding author on reasonable request and pending appropriate human subjects and confidentiality protections.

\section{Ethics approval and consent to participate}

This study was approved by the Human Research Protection Office at Washington University in St. Louis (\#201609029); all participants provided written informed consent.

Consent for publication

Not applicable

\section{Competing interests}

The authors declare that they have no competing interests.

\section{Author details}

${ }^{1}$ The Brown School, Washington University in St. Louis, 1 Brookings Dr, St. Louis, MO 63130, USA. ${ }^{2}$ Department of Medicine, Division of General Medical Sciences, Washington University School of Medicine, 4523 Clayton Avenue, Campus Box 8005, St. Louis, MO 63110, USA. ${ }^{3}$ Center for Human Nutrition, Department of Medicine, Washington University School of Medicine, 4523 Clayton Avenue, Campus Box 8031, St. Louis, MO 63110, USA. ${ }^{4}$ Division of Public Health Sciences, Washington University School of Medicine, 660 South Euclid Avenue, Campus Box 8100, St Louis, MO 63110, USA. ${ }^{5}$ Division of Public Health Sciences and Alvin J. Siteman Cancer Center, Department of Surgery, Washington University School of Medicine, Washington University in St. Louis, 660 South Euclid Avenue, Campus Box 8100, St. Louis, MO 63110, USA.

Received: 28 August 2019 Accepted: 13 April 2020

Published online: 28 April 2020

\section{References}

1. Galobardes B, Morabia A, Bernstein MS. The differential effect of education and occupation on body mass and overweight in a sample of working people of the general population. Ann Epidemiol. 2000;10(8):532-7.

2. Sarlio-Lahteenkorva S, Silventoinen K, Lahelma E. Relative weight and income at different levels of socioeconomic status. Am J Public Health. 2004;94(3):468-72.

3. Everson SA, Maty SC, Lynch JW, Kaplan GA. Epidemiologic evidence for the relation between socioeconomic status and depression, obesity, and diabetes. J Psychosom Res. 2002;53(4):891-5.

4. Mokdad AH, Ford ES, Bowman BA, Dietz WH, Vinicor F, Bales VS, et al. Prevalence of obesity, diabetes, and obesity-related health risk factors, 2001. JAMA. 2003;289(1):76-9.

5. Flegal KM, Carroll MD, Ogden CL, Curtin LR. Prevalence and trends in obesity among US adults, 1999-2008. JAMA. 2010;303(3):235-41.

6. Choi B, Schnall P, Dobson M, Yang H, Baker D, Seo Y. A socioecological framework for research on work and obesity in diverse urban transit 
operators based on gender, race, and ethnicity. Ann Occup Environ Med. 2017;29:15.

7. Conn VS, Hafdahl AR, Cooper PS, Brown LM, Lusk SL. Meta-analysis of workplace physical activity interventions. Am J Prev Med. 2009;37(4):330-9.

8. You W, Almeida FA, Zoellner JM, Hill JL, Pinard CA, Allen KC, et al. Who participates in internet-based worksite weight loss programs? BMC Public Health. 2011;11:709.

9. Sorensen G, Stoddard A, Ockene JK, Hunt MK, Youngstrom R. Worker participation in an integrated health promotion/health protection program: results from the WellWorks project. Health Educ Q. 1996;23(2):191-203.

10. Heinen $L$, Darling $H$. Addressing obesity in the workplace: the role of employers. Milbank Q. 2009;87(1):101-22.

11. Gabel JR, Whitmore H, Pickreign J, Ferguson CC, Jain A, S K, et al. Obesity and the workplace: current programs and attitudes among employers and employees. Health Aff (Millwood). 2009;28(1):46-56.

12. Morris WR, Conrad KM, Marcantonio RJ, Marks BA, Ribisl KM. Do blue-collar workers perceive the worksite health climate differently than white-collar workers? Am J Health Promot. 1999;13(6):319-24.

13. Conrad P. Wellness in the work place: potentials and pitfalls of work-site health promotion. Milbank Q. 1987;65(2):255-75.

14. Glasgow R, McCaul K, Fisher K. Participation in worksite health promotion: a critique of the literature and recommendations for future practice. Health Ed Q. 1993:20(3):391-408.

15. US Department of Health and Human Services. Healthy People 2020 Washington, DC: US Department of Health and Human Services; 2017 [Available from: http://www.healthypeople.gov/2020/default.aspx.

16. Gebhardt DL, Crump C. Employee fitness and wellness programs in the workplace. Am Psychol. 1990;45(2):262-72.

17. Linnan L, Tate DF, Harrington CB, Brooks-Russell A, Finkelstein E, Bangdiwala $\mathrm{S}$, et al. Organizational-and employee-level recruitment into a worksitebased weight loss study. Clinical Trials. 2012;9(2):215-25.

18. Baron SL, Beard S, Davis LK, Delp L, Forst L, Kidd-Taylor A, et al. Promoting integrated approaches to reducing health inequities among low-income workers: applying a social ecological framework. Am J Ind Med. 2014;57(5): 539-56.

19. Rongen A, Robroek SJ, van Ginkel W, Lindeboom D, Altink B, Burdorf A. Barriers and facilitators for participation in health promotion programs among employees: a six-month follow-up study. BMC Public Health. 2014; 14:573.

20. Dodson EA, Hipp JA, Gao M, Tabak RG, Yang L, Brownson RC. The impact of worksite supports for healthy eating on dietary behaviors. J Occup Environ Med. 2016;58(8):e287-93.

21. Anderson LM, Quinn TA, Glanz K, Ramirez G, Kahwati LC, Johnson DB, et al. The effectiveness of worksite nutrition and physical activity interventions for controlling employee overweight and obesity: a systematic review. Am Prev Med. 2009;37(4):340-57.

22. O'Donnell M. Does workplace health promotion work or not? Are you sure you really want to know the truth? Am J Health Promot. 2013;28(1):iv-vi.

23. Meng L, Wolff MB, Mattick KA, DeJoy DM, Wilson MG, Smith ML. Strategies for worksite health interventions to employees with elevated risk of chronic diseases. Safety Health Work. 2017;8(2):117-29.

24. Rongen A, Robroek SJ, van Lenthe FJ, Burdorf A. Workplace health promotion: a meta-analysis of effectiveness. Am J Prev Med. 2013;44(4):406-15.

25. Hutchinson AD, Wilson C. Improving nutrition and physical activity in the workplace: a meta-analysis of intervention studies. Health Promot Int. 2012; 27(2):238-49.

26. Cairns JM, Bambra C, Hillier-Brown FC, Moore HJ, Summerbell CD. Weighing up the evidence: a systematic review of the effectiveness of workplace interventions to tackle socio-economic inequalities in obesity. J Public Health (Oxford, England). 2015;37(4):659-70.

27. Brownson RC, Jacobs JA, Tabak RG, Hoehner CM, Stamatakis KA. Designing for dissemination among public health researchers: findings from a national survey in the United States. Am J Public Health. 2013;103(9):1693-9.

28. American College of Cardiology/American Heart Association Task Force on Practice Guidelines OEP. Executive summary: Guidelines (2013) for the management of overweight and obesity in adults: a report of the American College of Cardiology/American Heart Association Task Force on Practice Guidelines and the Obesity Society published by the Obesity Society and American College of Cardiology/American Heart Association Task Force on Practice Guidelines. Based on a systematic review from the The Obesity Expert Panel, 2013. Obesity (Silver Spring). 2014;22(Suppl 2):S5-39.
29. Liu F, Kong X, Cao J, Chen S, Li C, Huang J, et al. Mobile phone intervention and weight loss among overweight and obese adults: a meta-analysis of randomized controlled trials. Am J Epidemiol. 2015;181(5):337-48.

30. Lewis $Z H$, Lyons EJ, Jarvis JM, Baillargeon J. Using an electronic activity monitor system as an intervention modality: a systematic review. BMC Public Health. 2015;15(1):585.

31. King AC, Glanz K, Patrick K. Technologies to measure and modify physical activity and eating environments. Am J Prev Med. 2015;48(5):630-8.

32. Bennett GG, Steinberg DM, Stoute C, Lanpher M, Lane I, Askew S, et al. Electronic health (eHealth) interventions for weight management among racial/ethnic minority adults: a systematic review. Obes Rev. 2014;15(Suppl 4):146-58.

33. Patrick K, Raab F, Adams MA, Dillon L, Zabinski M, Rock $C L$, et al. A text message-based intervention for weight loss: randomized controlled trial. J Med Internet Res. 2009:11(1):e1.

34. Haapala I, Barengo NC, Biggs S, Surakka L, Manninen P. Weight loss by mobile phone: a 1-year effectiveness study. Public Health Nutrition. 2009; 12(12):2382-91.

35. Pop-Eleches C, Thirumurthy H, Habyarimana JP, Zivin JG, Goldstein MP, de Walque $\mathrm{D}$, et al. Mobile phone technologies improve adherence to antiretroviral treatment in a resource-limited setting: a randomized controlled trial of text message reminders. AIDS. 2011;25(6):825-34.

36. Woolford SJ, Clark SJ, Strecher VJ, Resnicow K. Tailored mobile phone text messages as an adjunct to obesity treatment for adolescents. J Telemed Telecare. 2010;16(8):458-61.

37. Gerber BS, Stolley MR, Thompson AL, Sharp LK, Fitzgibbon ML. Mobile phone text messaging to promote healthy behaviors and weight loss maintenance: a feasibility study. Health Informatics J. 2009;15(1):17-25.

38. Tabak RG, Strickland JR, Stein RI, Dart H, Colditz GA, Kirk B, et al. Development of a scalable weight loss intervention for low-income workers through adaptation of interactive obesity treatment approach (iOTA). BMC Public Health. 2018;18(1):1265.

39. Greaney ML, Quintiliani LM, Warner ET, King DK, Emmons KM, Colditz GA, et al. Weight management among patients at community health centers: the "Be Fit, Be Well" study. Obes Weight Manag. 2009;5(5):222-8.

40. Bennett GG, Warner ET, Glasgow RE, Askew S, Goldman J, Ritzwoller DP, et al. Obesity treatment for socioeconomically disadvantaged patients in primary care practice. Arch Intern Med. 2012;172(7):565-74.

41. Stein Rl, Strickland JR, Tabak RG, Dale AM, Colditz GA, Evanoff BA. Design of a randomized trial testing a multi-level weight-control intervention to reduce obesity and related health conditions in low-income workers. Contemp Clin Trial. 2019;79:89-97.

42. Gans KM, Risica PM, Wylie-Rosett J, Ross EM, Strolla LO, McMurray J, et al. Development and evaluation of the nutrition component of the Rapid Eating and Activity Assessment for Patients (REAP): a new tool for primary care providers. J Nutr Educ Behav. 2006;38(5):286-92.

43. Segal-Isaacson CJ, Wylie-Rosett J, Gans KM. Validation of a short dietary assessment questionnaire: the Rapid Eating and Activity Assessment for Participants short version (REAP-S). Diabetes Educ. 2004;30(5):774, 6, 8 passim.

44. Craig CL, Marshall AL, Sjostrom M, Bauman AE, Booth ML, Ainsworth BE, et al. International physical activity questionnaire: 12-country reliability and validity. Med Sci Sports Exerc. 2003;35(8):1381-95.

45. The International Physical Activity Questionnaire [updated 2019. Available from: https://sites.google.com/site/theipaq/home.

46. Ricci-Cabello I, Bobrow K, Islam SMS, Chow CK, Maddison R, Whittaker R, et al. Examining development processes for text messaging interventions to prevent cardiovascular disease: systematic literature review. JMIR Mhealth Uhealth. 2019;7(3):e12191.

47. Ross KM, Wing RR. Implementation of an internet weight loss program in a worksite setting. J Obes. 2016;2016:9372515.

48. Harvey J, Krukowski R, Priest J, West D. Log often, lose more: electronic dietary self-monitoring for weight loss. Obesity (Silver Spring). 2019;27(3): 380-4.

49. Olson CM, Strawderman MS, Graham ML. Use of an online diet goal-setting tool: relationships with gestational weight gain. J Nutr Educ Behav. 2019; 51(4):391-9.

50. Mao AY, Chen C, Magana C, Caballero Barajas K, Olayiwola JN. A mobile phone-based health coaching intervention for weight loss and blood pressure reduction in a national payer population: a retrospective study. JMIR Mhealth Uhealth. 2017;5(6):e80. 
51. Song Z, Baicker K. Effect of a workplace wellness program on employee health and economic outcomes: a randomized clinical trial. JAMA. 2019; 321(15):1491-501.

52. Fischer HH, Fischer IP, Pereira RI, Furniss AL, Rozwadowski JM, Moore SL, et al. Text message support for weight loss in patients with prediabetes: a randomized clinical trial. Diabetes Care. 2016;39(8):1364-70

53. Schoeller DA. The effect of holiday weight gain on body weight. Physiol Behav. 2014;134:66-9.

54. Cook CM, Subar AF, Troiano RP, Schoeller DA. Relation between holiday weight gain and total energy expenditure among 40- to 69-y-old men and women (OPEN study). Am J Clin Nutr. 2012;95(3):726-31.

55. Stevenson JL, Krishnan S, Stoner MA, Goktas Z, Cooper JA. Effects of exercise during the holiday season on changes in body weight, body composition and blood pressure. Eur J Clin Nutr. 2013;67(9):944-9.

56. Yanovski JA, Yanovski SZ, Sovik KN, Nguyen TT, O'Neil PM, Sebring NG. A prospective study of holiday weight gain. N Engl J Med. 2000;342(12):861-7.

57. Andersson I, Rössner S. The Christmas factor in obesity therapy. Int J Obes Relat Metab Disord. 1992;16(12):1013-5.

\section{Publisher's Note}

Springer Nature remains neutral with regard to jurisdictional claims in published maps and institutional affiliations.

Ready to submit your research? Choose BMC and benefit from:

- fast, convenient online submission

- thorough peer review by experienced researchers in your field

- rapid publication on acceptance

- support for research data, including large and complex data types

- gold Open Access which fosters wider collaboration and increased citations

- maximum visibility for your research: over $100 \mathrm{M}$ website views per year

At BMC, research is always in progress.

Learn more biomedcentral.com/submissions 